\title{
LEVANTAMENTO FITOSSOCIOLOGICO DE PLANTAS DANINHAS APÓS A APLICAÇÃO DE DIFERENTES MISTURAS DE TANQUE COM FLUAZIFOPE EM ÁREA DE CULTIVO DE MANDIOCA
}

\author{
VICENTE BEZERRA PONTES JUNIOR, \\ ALESSANDRO DA COSTA LIMA, \\ LEANDRO DO ROSARIO SILVA, \\ DANIEL COSTA NOGUEIRA, \\ FRANCISCO RONALDO CARDOSO DA SILVA, \\ MARTINHO MELO FIGUEIREDO, \\ TREYCE STEPHANE CRISTO TAVARES, \\ PHELIPE HENRIQUE COSTA DE MIRANDA, \\ GABRIELA TAVARES PIRES, \\ RAFAEL GOMES VIANA.
}

\begin{abstract}
RESUMO - A presença de plantas daninhas na cultura da mandioca configura-se como um dos principais fatores atrelado ao baixo incremento na produção desta cultura, uma vez que, o crescimento inicial lento de grande parte das plantas cultivadas, facilita a competição com plantas daninhas, levando à redução da produtividade e consequentemente do lucro da produção. Objetivou-se com este trabalho realizar o levantamento fitossociológico de plantas daninhas, após a aplicação de diferentes misturas de tanque com fluazifop-P-Butil em área de cultivo de mandioca. Os tratamentos constituíram-se pela combinação de: Fluazifop-P-Butílico; Fluazifop-P-Butílico + Metsulfuron Metílico; Fluazifop-P-Butílico + Isoxaflutol; Fluazifope-P-Butílico + Flumioxazina e Controle (sem herbicida). Para o estudo fitossociológico, utilizouse o método do quadrado inventário, aplicado por meio de um quadrado de $0,5 \mathrm{~m} \times 0,5 \mathrm{~m}$, lançado ao acaso, totalizando quatro lançamentos por tratamento. Com os dados obtidos, foi possível efetuar os cálculos de parâmetros fitossociológicos, entre eles o índice de valor de importância (IVI) de cada espécie, assim como, o agrupamento hierárquico de similaridade, pelo método UPGMA. Concluiu-se que o tratamento composto apenas pelo herbicida Fluazifop-P-Butílico apresentou o melhor controle para as plantas invasoras, principalmente a da espécie Paspalum maritimum, que apresentou os maiores valores de IVI.
\end{abstract}

PALAVRAS-CHAVE - Herbicida; Mistura de tanque, Controle químico de plantas daninhas.

\section{INTRODUÇÃO}

Nas últimas duas décadas o Estado do Pará destacou-se no cenário nacional como o maior produtor de mandioca, com produção, em 2014, superior a 4,8 milhões de toneladas de raízes, respondendo por $60 \%$ da produção da região Norte e $21 \%$ da produção brasileira. Porém, considerando o excelente potencial da cultura, a sua produtividade média, em torno de 14,7 t/ha, ainda está abaixo do que a planta consegue produzir se manejada de forma adequada [11].

Diversos fatores contribuem para uma baixa produtividade, principalmente no manejo da mandiocultura. Por se tratar de uma cultura rústica, muitos produtores acabam negligenciando alguns cuidados, como o controle de plantas daninhas. Entretanto, a presença dessas plantas na área de cultivo pode resultar em redução no número, na massa seca e no teor de amido de raízes de mandioca [17].

A cultura está sujeita a vários ciclos de infestação de plantas daninhas, estas são favorecidas ainda pela arquitetura da copa, pelo espaçamento de cultivo e pelo lento crescimento inicial da mandioca [17]. O serviço de capinas na área da plantação acarreta um grande prejuízo econômico, por se tratar de um método de controle pouco eficaz, pois muitas plantas daninhas são assexuadas e se propagam pelo método vegetativo. Por isso, a necessidade de encontrar novos produtos que façam o combate de plantas daninhas e facilitem o manejo da mandiocultura.

A fim de estimar a população de plantas daninhas, utilizase a fitossociologia que é o estudo realizado pelos profissionais das ciências agrárias para fazer o reconhecimento das comunidades infestantes de plantas. Para Erasmo et al [10], 
estudos fitossociológicos permitem avaliar a composição da vegetação, adquirindo dados sobre frequência, densidade, abundância, índice de importância relativa e coeficiente de similaridade das espécies constatadas e fazer diversas inferências sobre as mesmas.

Existem diversas alternativas para efetuar o controle populacional dessas plantas, sendo o controle químico bastante utilizado. Porém, para a cultura da mandioca, necessita-se de mais pesquisas, pois, atualmente, são registrados poucos herbicidas para cultura [1], um deles, possui o nome comercial de Fusildade 250 EW. Este, possui como princípio ativo o Fluazifope-P-Butílico que é um herbicida inibidor da enzima acetil-CoA carboxilase (ACCase) utilizado no controle de gramíneas em culturas dicotiledôneas. Devido a inibição desta enzima, há o bloqueio da síntese de lipídeos nas plantas suscetíveis [5].

Os herbicidas utilizados na agricultura não têm espectro de ação capaz de controlar o conjunto de problemas fitossanitários, o que faz com que os agricultores usem diferentes moléculas de uma só vez, tornando as misturas de tanque uma prática comum. Além disso, existem algumas combinações de produtos que podem ter efeitos sinérgicos, ou seja, um produto ajuda o outro a funcionar de forma mais eficiente do que se fosse aplicado de maneira isolada [11].

Desta forma, este trabalho objetivou realizar o levantamento fitossociológico de plantas daninhas após a aplicação de diferentes misturas de tanque com fluazifop-P-Butil em área de cultivo de mandioca no município de Castanhal, no estado do Pará.

\section{METODOLOGIA}

$\mathrm{O}$ trabalho foi realizado no campo experimental da Fazenda Escola de Castanhal-PA, da Universidade Federal Rural da Amazônia. O município de Castanhal tem um clima tropical e uma pluviosidade significativa ao longo do ano, mesmo no mês mais seco. De acordo a classificação de Köppen, o clima da localidade é do tipo Af e as temperaturas médias anuais são de $26.5^{\circ} \mathrm{C}$ e pluviosidade média anual de $2432 \mathrm{~mm}$.

$\mathrm{O}$ trabalho foi realizado em campo com solo classificado como Latossolo Amarelo distrófico, com base no mapeamento da EMBRAPA Amazônia Oriental, apresentando as seguintes características químicas em profundidade de 20 cm: pH em H2O: 3,7; P: $81 \mathrm{mg} \mathrm{dm}^{-3}$; K: $23 \mathrm{mg} \mathrm{dm}^{-3}$; Ca: $1,9 \mathrm{cmolc} \mathrm{dm}^{-3}$; $\mathrm{Ca}+\mathrm{Mg}: 2,4 \mathrm{cmolc} \mathrm{dm}^{-3}$; Na: $10 \mathrm{mg} \mathrm{dm}^{-3}$; Al: 0,2 cmolc dm ${ }^{-3}$; $\mathrm{H}+\mathrm{Al}: 3,77 \mathrm{cmolc} \mathrm{dm}^{-3}$.

O plantio foi realizado em sistema convencional, com duas arações e uma gradagem niveladora. A cultivar de mandioca utilizada no plantio foi a Poti, no qual possui grande potencial produtivo na região. Conforme análise do solo, não foram necessários a realização de calagem e adubação fosfatada, apenas foram feitas a adubação potássica com aplicação de cloreto de potássio $\left(100 \mathrm{~kg} \mathrm{ha}^{-1}\right)$ e nitrogenada com ureia $\left.\left(89 \mathrm{~kg} \mathrm{ha}^{-1}\right)\right)$ parcelados aos 30, 70 e 110 dias após o plantio. O plantio foi realizado com o uso de plantadeira mecanizada regulada em espaçamento entre linhas de $0,9 \mathrm{~m}$ e $1,0 \mathrm{~m}$ entre plantas, com densidade de 11.111 plantas ha-
1. O delineamento experimental utilizado foi em blocos ao acaso com cinco tratamentos e quatro repetições (Tabela 1). Os tratamentos constituíram-se pela combinação de quatro herbicidas, e uma testemunha sem aplicação de herbicida (Tabela 2).

Tabela 1. Tratamentos, dose correspondente e sigla usada em gráficos em tabelas.

\begin{tabular}{|l|c|c|}
\hline \multicolumn{1}{|c|}{ Tratamentos } & Dose $^{*}$ & Sigla \\
\hline $\begin{array}{l}\text { Fluazifope-P-Butílico } \\
\text { + Metsulfuron Metílico }\end{array}$ & $250 \mathrm{~g}+3 \mathrm{~g}$ & $\mathrm{~F}+\mathrm{M}$ \\
\hline $\begin{array}{l}\text { Fluazifope-P-Butílico } \\
\text { + Isoxaflutol }\end{array}$ & $250 \mathrm{~g}+93,75 \mathrm{~g}$ & $\mathrm{~F}+\mathrm{I}$ \\
\hline $\begin{array}{l}\text { Fluazifope-P-Butílico } \\
\text { + Flumioxazina }\end{array}$ & $250 \mathrm{~g}+50 \mathrm{~g}$ & F+FLU \\
\hline Fluazifope-P-Butílico & $250 \mathrm{~g}$ & $\mathrm{~F}$ \\
\hline Controle (sem herbicida) & & Controle \\
\hline
\end{tabular}

*g i.a. em equivalente ácido $\mathrm{ha}^{-1}$.

Tabela 2. Características dos herbicidas utilizados nos tratamentos.

\begin{tabular}{|l|l|l|}
\hline Nome Comercial & $\begin{array}{l}\text { Ingrediente } \\
\text { Ativo }\end{array}$ & $\begin{array}{l}\text { Concentração } \\
\text { (g de i.a) }\end{array}$ \\
\hline Fusilade ${ }^{\circledR}$ & $\begin{array}{l}\text { Fluazifope-p- } \\
\text { butílico }\end{array}$ & $250 \mathrm{~g} \mathrm{~L}^{-1}$ \\
\hline Provence $\AA$ & Isoxaflutol & $750 \mathrm{~g} \mathrm{~kg}^{-1}$ \\
\hline Flumyzin ${ }^{-1}$ & Flumioxazina & $500 \mathrm{~g} \mathrm{~kg}^{-1}$ \\
\hline Zartan ${ }^{\circledR}$ & $\begin{array}{l}\text { Metsufuron me- } \\
\text { tílico }\end{array}$ & $600 \mathrm{~g} \mathrm{~kg}^{-1}$ \\
\hline
\end{tabular}

No preparo dos tratamentos foram utilizadas as proporções da mistura dos produtos para aplicação de $100 \mathrm{~L}$ de calda por hectare. A aplicação dos tratamentos foi feita com pulverizador pressurizado por $\mathrm{CO} 2$, com velocidade de 4 $\mathrm{km} / \mathrm{h}$ e pressão de 50 lib $\mathrm{pol}^{-2}$, com barra de $50 \mathrm{~cm} \mathrm{de}$ largura, munida de duas pontas de pulverização de duplo leque AD-IA 11002. Para o estudo fitossociológico, utilizouse o método do quadrado inventário, aplicado por meio de um quadrado de $50 \mathrm{~cm}$ de lado, lançado ao acaso uma vez em cada repetição, totalizando quatro lançamentos por tratamento e $1 \mathrm{~m}^{2}$ de área. A cada lançamento, as espécies encontradas dentro do quadrado foram colhidas e devidamente identificadas, classificadas e cadastradas.

Além desses cálculos, foi determinado o índice de valor de importância (IVI) proposto por [8] que estabelece uma correlação entre as variáveis parciais, transformando-as em uma expressão única e simples, expondo a importância relativa de cada espécie.

Utilizou-se o índice de Jaccard para construção de um dendrograma baseado no agrupamento dos dados, sendo construído com base no método de média do grupo (UPGMA). O agrupamento foi feito a partir da média aritmética dos seus elementos, utilizando o programa PAST.

Os parâmetros utilizados na análise foram os descritos por [13]: 


$$
\begin{gathered}
\text { Frequncia }(\text { Fre })=\frac{\mathrm{N}^{\circ} \text { de parcelas que contêm o indivíduo }}{\mathrm{N}^{\circ} \text { total de parcelas utilizadas }} \\
\text { Densidade }(\text { Den })=\frac{\mathrm{N}^{\circ} \text { total de indivíduos por espécie }}{\text { Área total amostrada }}
\end{gathered}
$$$$
\text { Abundncia }(A b u)=\frac{\mathrm{N}^{\circ} \text { total de indivíduos por espécie }}{\mathrm{N}^{\circ} \text { total de parcelas que contêm a espécie }}
$$$$
\text { Frequnciarelativa }(F r r)=\frac{\text { Frequência da espécie x100 }}{\text { Frequência total de todas as espécies }}
$$

$$
\text { Densidaderelativa }(\text { Der })=\frac{\text { Densidade da espécie x100 }}{\text { Densidade total das espécies }}
$$

$$
\text { Abundnciarelativa }(A b r)=\frac{\text { Abundância da espécie x100 }}{\text { Abundância total de todas as espécies }}
$$

Índice de Valor de Importância (IVI) = Frr + Der + Abr

\section{RESULTADOS E DISCUSSÃO}

Após o levantamento, constatou-se que a área apresentava um total de 4 famílias botânicas, representadas por 9 espécies de plantas daninhas. As famílias que apresentaram o maior número de indivíduos foram a Cyperaceae e a Poaceae com quatro e três espécies, respectivamente.

A partir da tabela 3, é possível inferir que $80 \%$ das espécies possuem um ciclo de vida perene, apenas uma espécie possui ciclo de vida anual, Cleome aculeata. Todas as espécies, possuem consistência do caule herbácea.

Tabela 3. Relação de plantas daninhas identificadas por família, espécie e nome comum.

\begin{tabular}{|l|l|l|}
\hline Família & Espécie & Nome Comum \\
\hline Cleomaceae & Cleome aculeata & Xinxim-de-galinha \\
\hline Cyperaceae & $\begin{array}{l}\text { Cyperus aggre- } \\
\text { gatus }\end{array}$ & Tiririca \\
\hline Cyperaceae & Cyperus diffusus & Junquinho \\
\hline Cyperaceae & Cyperus flavus & Junquinho \\
\hline Euphorbiaceae & $\begin{array}{l}\text { Sebastiania cor- } \\
\text { niculata }\end{array}$ & Granxuma-dechifre \\
\hline Poaceae & $\begin{array}{l}\text { Brachiaria sub- } \\
\text { quadripara }\end{array}$ & Tenner-grass \\
\hline Poaceae & $\begin{array}{l}\text { Paspalum mari- } \\
\text { timum }\end{array}$ & Capim-gengibre \\
\hline Poaceae & $\begin{array}{l}\text { Pennisetum pur- } \\
\text { purium }\end{array}$ & Capim-elefante \\
\hline Urticaceae & $\begin{array}{l}\text { Cecropia } \\
\text { pachystachya }\end{array}$ & Embaúba \\
\hline
\end{tabular}

Conforme observado na tabela 4, verificou-se que após a aplicação dos herbicidas, a espécie Paspalum maritimum apresentou os maiores valores analisados em: densidade, abundância e frequência nos tratamentos Fluazifope-
P-Butílico + Metsulfurom Metílico e Fluazifope-P-Butílico + Isoxaflutol. SOUZA (2006) afirma que há potencial atividade alelopática para $P$. maritimum em extrato bruto hidroalcoólico de folhas e rizomas e em solo coletado em área vegetada por essa planta daninha, isto demonstra que o grau de agressividade da planta e a velocidade com que essa espécie pode invadir e dominar uma área.

A espécie Xixim-de-galinha (Cleome aculeata) somente não está presente no tratamento Fluazifope-P-Butílico + Isoxaflutol. Essa planta possui como característica elevada rusticidade, desenvolvendo mesmo em solos de baixa fertilidade, em afloramentos rochosos, campos rupestres, áreas brejosas e orlas de florestas ( [7] e [3]).

De acordo com Duarte et al. [9], o índice de valor de importância (IVI), representado pelo somatório da densidade relativa, da frequência relativa e da dominância relativa, indica qual espécie tem maior influência dentro de uma comunidade. A espécie Paspalum Maritimum apresentou, em dois tratamentos, os maiores valores de IVI, o que pode ser explicado por Carvalho Filho e colaboradores [6], no qual afirmam que a espécie é considerada como uma das principais espécies concorrentes em nutrientes e umidade, em razão de seu hábito de crescimento rizomatoso e estolonífero e de sua grande capacidade de produção de sementes, essa planta é tida como de difícil erradicação.
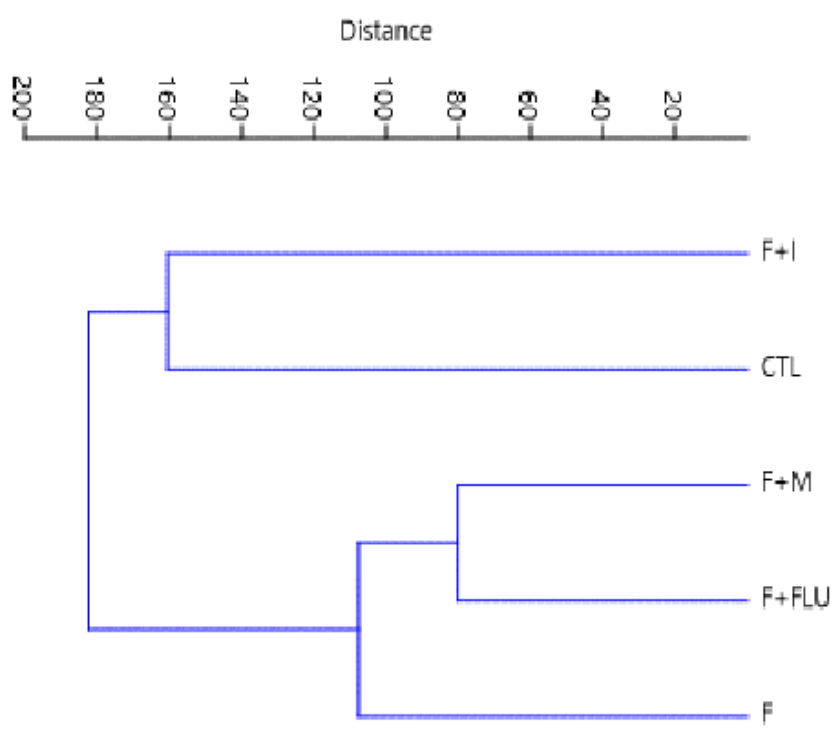

Figura 1. Dendrograma de similaridade construído pelo método de agrupamento pela média do grupo (UPGMA) da densidade de plantas daninhas em cinco tratamentos, obtido pelo software PAST, utilizando como coeficiente o índice de Jaccard.

A família cyperaceae também apresentou valores significativos de IVI, sendo a espécie Cyperus Aggregatus a que exibiu o mais alto valor. Isso pode ser explica pelo fato do gênero cyperus demonstrar ampla adaptabilidade a muitos ambientes agrícolas, por ser perene e pela capacidade de se reproduzir sexuada e assexuadamente [15]. Isto demonstra a enorme dificuldade em controlar as espécies, visto que os seus propágulos persistem no solo, adormecidos por longos 
Tabela 4. Número de indivíduos (NTI), Valores de frequência (Fre, densidade (Den) abundância (Abu), frequência relativa (Frr), densidade relativa (Der), abundância relativa (Abr), índice de valor de importância (Ivl), das plantas daninhas no sistema de plantio de mandioca.

\begin{tabular}{|c|c|c|c|c|c|c|c|c|}
\hline \multirow{3}{*}{ Espécie } & \multicolumn{8}{|c|}{ Tratamento } \\
\hline & NTI & Fre & Den & Abu & Frr & Der & Abr & IVI \\
\hline & \multicolumn{8}{|c|}{ Fluazifope-P-Butílico + Metsulfurom Metílico } \\
\hline Paspalum maritimum & 66,0 & 75,0 & 16,5 & 22,0 & 33,3 & 80,5 & 62,0 & 175,8 \\
\hline Cleome aculeata & 50,0 & 1,3 & 2,5 & 22,2 & 6,1 & 7,0 & 35,4 & \\
\hline Cyperus aggregatus & 25,0 & 1,0 & 4,0 & 11,1 & 4,9 & 11,3 & 27,3 & \\
\hline Cecropia pachysta. & 6,0 & 25,0 & 1,5 & 1,0 & 11,1 & 1,2 & 2,8 & 15,1 \\
\hline Brachiaria subquadrip. & 1,0 & 25,0 & 0,3 & 1,0 & 11,1 & 7,2 & 3,0 & 21,3 \\
\hline Cyperus diffusus & 25,0 & 1,3 & 5,0 & 11,1 & 6,0 & 14,9 & 31,3 & \\
\hline \multirow[t]{2}{*}{ Total } & 83,0 & 225,0 & 20,8 & 33,5 & 100,0 & 100,0 & 100,0 & 300,0 \\
\hline & \multicolumn{8}{|c|}{ Fluazifope-P-Butílico + Isoxaflutol } \\
\hline Paspalum maritimum & 211,0 & 75,0 & 52,8 & 70,3 & 50,0 & 89,0 & 73,8 & 212,8 \\
\hline Cyperus flavus & 2,0 & 50,0 & 0,5 & 1,0 & 33,3 & 0,8 & 1,0 & 35,2 \\
\hline Cyperus aggregatus & 24,0 & 25,0 & 6,0 & 24,0 & 16,7 & 10,1 & 25,2 & 52,0 \\
\hline \multirow[t]{2}{*}{ Total } & 237,0 & 150,0 & 59,3 & 95,3 & 100,0 & 100,0 & 100,0 & 300,0 \\
\hline & \multicolumn{8}{|c|}{ Fluazifope-P-Butílico + Flumioxazina } \\
\hline Cyperus diffusus & 43,0 & 100,0 & 11,0 & 10,83 & 40,0 & 53,8 & 42,3 & 136,0 \\
\hline Cleome aculeata & 6,0 & 50,0 & 2,0 & 0 & 20,0 & 7,5 & 11,8 & 9,3 \\
\hline Sebastiania corniculata & 2,0 & 25,0 & 1,0 & 2,0 & 10,0 & 2,5 & 7,9 & 20,4 \\
\hline Cyperus aggregatus & 29,0 & 75,0 & 7,0 & 9,7 & 30,0 & 36,3 & 38,8 & 104,3 \\
\hline \multirow[t]{2}{*}{ Total } & 80,0 & 250,0 & 20,0 & 25,4 & 100,0 & 100,0 & 100,0 & 300,0 \\
\hline & \multicolumn{8}{|c|}{ Fluazifope-P-Butílico } \\
\hline Cyperus aggregatus & 109,0 & 75,0 & 27,3 & 36,0 & 50,0 & 93,2 & 93,2 & 236,36 \\
\hline Cleome aculeata & 8,0 & 75,0 & 2,0 & 32,7 & 50,0 & 6,8 & 6,8 & 3,7 \\
\hline \multirow[t]{2}{*}{ Total } & 117,0 & 150,0 & 29,3 & 39,0 & 100,0 & 100,0 & 100 & 300,0 \\
\hline & \multicolumn{8}{|c|}{ Controle (Sem Herbicidas) } \\
\hline Cleome aculeata & 9,0 & 75,0 & 2,3 & 2,3 & 13,6 & 2,0 & 1,9 & 17,6 \\
\hline Cecropia pachysta. & 9,0 & 50,0 & 2,3 & 2,3 & 9,1 & 2,4 & 2,3 & 13,7 \\
\hline Cyperus diffusus & 43,0 & 100,0 & 10,8 & 10,8 & 18,2 & 9,6 & 9,2 & 37,0 \\
\hline Brachiaria subquad & 83,0 & 75,0 & 20,8 & 20,8 & 13,6 & 18,6 & 17,7 & 49,9 \\
\hline Cyperus flavus & 35,0 & 50,0 & 8,8 & 17,5 & 9,1 & 10,5 & 14,9 & 34,6 \\
\hline Cyperus aggreg. & 65,0 & 100,0 & 16,3 & 16,3 & 18,2 & 14,6 & 13,9 & 46,6 \\
\hline Paspalum maritim. & 121,0 & 100,0 & 30,3 & 30,3 & 18,2 & 27,1 & 25,8 & 71,1 \\
\hline Total & 365,0 & 550,0 & 108,5 & 117,3 & 100,0 & 100,0 & 100,0 & 300,0 \\
\hline
\end{tabular}

períodos de tempo.

Observa-se na tabela 2, que o tratamento Fluasifope + metsulforan foram encontradas as famílias Poaceae; cyperaceae; urticaceae e cleomaceae; o que mostra que o fluasifope não surtiu efeito no controle as gramíneas e o metsulfuron não foi eficaz no controle de plantas de folhas largas pelo aparecimento de Cecropia pachystachya. Isto contrasta com que relata BOREM [4] que o herbicida à base de metsulfuron-metil é eficaz no controle de várias espécies daninhas magnoliopsidas. Esses resultados corroboram a ideia de OLIVEIRA et al. [14], onde afirmam que, eventualmente, pode ocorrer algum antagonismo quando estes graminicidas aplicados em pósemergência são misturados em tanque com outros herbicidas latifolicidas.

Conforme o Dendrograma (Figura 1), o tratamento Flazifop-P-Butílico + Isoxaflutol foi o que demonstrou maior similaridade com o tratamento controle. Sendo assim, essa mistura de tanque foi a que obteve menor eficiência no controle de plantas daninhas, apesar de ter reduzido a densidade de plantas, a interação entre esses herbicidas não foi eficiente no controle Paspalum maritimum, que obteve alto índice de ocorrência na área de plantio, assim como Cyperus flavus e Cyperus aggregatus. Em concordância com Alvarenga et al. (2018) ao verificar as interações entre herbicidas em plantio de milho $R R{ }^{\circledR}$ voluntário, foi observada que a mistura entre fluazifope-p-butílico com 2,4-D resultou em redução do nível de controle, em razão da incompatibilidade fisiológica na associação de inibidores da ACCase e mimetizadores de auxina, efeito denominado de antagonismo.

Os tratamentos Fluazifop-P-Butílico + Metsulfurom metílico e Fluazifop-P-Butílico + Flumioxazina formaram outro grupo de similaridade. Ambos os tratamentos reduziram consideravelmente a densidade de plantas daninhas, entretanto, a primeira mistura não controlou a espécie Paspalum Ma- 
ritimum e a segunda mistura não foi eficiente em controlar espécies Cyperus difussus e Cyperus aggregatus.

O tratamento composto apenas pelo herbicida FluazifopP-Butílico diferiu dos demais tratamentos, e apresentou o melhor controle das plantas invasoras, eliminando 7 das 9 espécies identificadas no tratamento controle, com exceção das espécies Cyperus aggregatus e Cleome aculeata.

\section{CONCLUSÕES}

Concluiu-se que o tratamento composto apenas pelo herbicida Fluazifop-P-Butílico apresentou o melhor controle para as plantas daninhas. As misturas de tanque entre o FluazifopP-Butílico e os demais herbicidas utilizados no experimento, não apresentaram um controle satisfatório das plantas daninhas, não apresentando efeito sinérgico ou aditivo.

\section{Referências}

[1] AGROFIT. Sistema de agrotóxicos fitossanitários. Disponível em: $<$ http://agrofit.agricultura.gov.br/agrofit_cons/principal_agrofit_cons $>$. Acesso em: 26 abr. 2021.

[2] ALVARENGA, D. R.; TEIXEIRA, M. F. F.; FREITAS, F. C. L.; PAIVA, M. C. G.; CARVALHO, M.R.N.; GONÇALVES, V. A. Interações entre herbicidas no manejo do milho RR® voluntário. Revista Brasileira de Milho e Sorgo, v. 17, n. 1, p. 122- 134, 2018.

[3] BFG 2015. Growing knowledge: an overview of Seed Plant diversity in Brazil. Rodriguésia 66(4): 1-29.

[4] BOREM, ALUIZIO; SCHEEREN, Pedro Luiz. TRIGO: DO PLANTIO A COLHEITA. Viçosa, MG: UFV, 2015. 260 p. v. 1. ISBN 978-85-7035621-5.

[5] BURKER, I.C. et al. A seedling assay to screen aryloxyphenoxypropionic acid and cyclohexanedione resistance in johnsongrass (Sorghum halepense). Weed Technology, v.20, n.4, p.950-955, 2006.

[6] CARVALHO FILHO, O.M. de C.; FONTES, Humberto Rollemberg; Crescimento e algumas características nutricionais do capim-gengibe (Paspalum maritimum Trind.). Aracaju: EMBRAPA, p.7. (EMBRAPA. Tabuleiros Costeiros. Boletim de pesquisa e desenvolvimento, 1), 2004.

[7] COSTA E SILVA, M.B. 2000. O gênero Cleome L. (Capparaceae Juss.) para o Brasil. Universidade Federal Rural de Pernambuco. Recife.

[8] CURTIS, J.T.; MCINTOSH, R.P. The interrelations of certain analytic and synthetic phytosociological characters. Ecology, Washington, v. 31, p. 434-455, 1950.

[9] DUARTE JUNIOR, J.B.; COELHO, F.C.; FREITAS, S.P. Dinâmica de populações de plantas daninhas na cana-de-açúcar em sistema de plantio direto e convencional. Semina: Ciências Agrárias, v. 30, n. 3, p. 595-612, 2009.

[10] ERASMO E.A.L., PINHEIRO L.L.A., COSTA N.V. Levantamento fitossociológico das comunidades de plantas infestantes em áreas de produção de arroz irrigado cultivado sob diferentes sistemas de manejo. Planta Daninha. 2004; 22:195-201.

[11] FEIL, B.E.M. Por que o produtor realiza as misturas de tanque? In: Misturas de tanque: importância, benefícios, dicas práticas e assertividade na aplicação. [S. 1.]: MAISSOJA, 21 mar. 2018. Disponível em: https://maissoja.com.br/misturas-de-tanque-importanciabeneficios-dicas-praticas-e-assertividade-na-aplicacao/. Acesso em: 27 abr. 2021.

[12] MODESTO JÚNIOR, Moisés de Souza. CULTURA DA MANDIOCA Aspectos socioeconômicos, melhoramento genético, sistemas de cultivo, manejo de pragas e doenças e agroindústria. 1. ed. BRASILIA, DF: EMBRAPA, 2016. 257 p. ISBN 978-85-7035-621-5.

[13] MUELLER-DOMBOIS, D.; ELLENBERG, H.A. Aims and methods of vegetation ecology. New York: John Wiley, 1974. 547 p.

[14] OLIVEIRA R.S.; et al. Biologia e Manejo de plantas daninhas. Curitiba, 2011.

[15] PANOZZO, L. E. et al. Métodos de manejo de cyperus esculentus na lavoura de arroz irrigado. Planta Daninha, v. 27, n. 1, p. 165-174, 2009.

[16] SILVA, F. L., SILVA, J. R., SILVA, L. R. P. Efeito do desmatamento e do programa de transferência de renda bolsa família na produção da mandioca (Manihot esculenta Crantz) no estado do Pará. Revista acadêmica de economia con el Numero Internacional Normalizado de Publicaciones Seriadas. ISSN 1696-8352, 2014

[17] SILVA, D. V.; SANTOS, J. B.; FERREIRA, E. A.; FRANÇA, A. C.; SILVA, A. A.; SEDIYAMA, T. Manejo de plantas daninhas na cultura da mandioca. Planta daninha, Viçosa, v. 30, n. 4, p. 901-910, 2012.

[18] SOUZA FILHO, A.P.S. Interferência potencialmente alelopática do capim-gengibre (Paspalum maritimum) em áreas de pastagens cultivadas. Planta Daninha, v. 24, p. 451, 2006.

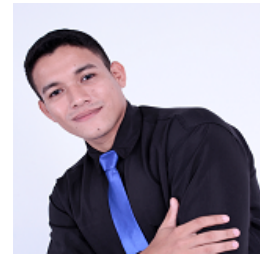

VICENTE BEZERRA PONTES JUNIOR

Engenheiro Agrônomo formado pela Universidade Federal Rural da Amazônia (UFRA), Belém - PA. Atuou em projetos de pesquisa, ensino e extensão no Programa de Educação Tutorial (PETAgronomia), com destaque para pesquisas com herbicidas na cultura da mandioca, projeto de clínica de atendimento à produtores rurais e produção de livros e trabalhos científicos. Atualmente é mestrando do programa de pós-graduação em Fitotecnia da Universidade Federal de Viçosa (UFV), atuando na área de comportamento de herbicidas no ambiente. Possui experiência em manejo integrado de plantas daninhas, comportamento de herbicidas no ambiente, tecnologia de aplicação de herbicidas, banco de sementes de plantas daninhas e processo produtivo da cultura da mandioca.

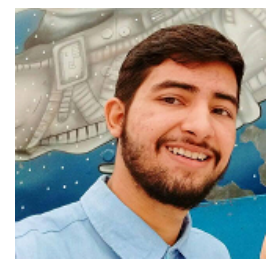

\section{ALESSANDRO DA COSTA LIMA}

Engenheiro Agrônomo pela Universidade Federal Rural da Amazônia (2019). Mestrando em Fitotecnia pela Universidade Federal de Viçosa (20192021). É membro do grupo de Manejo Integrado de Plantas Daninhas - UFV, orientado pelo $\mathrm{Dr}^{\circ}$ Kassio Ferreira Mendes. Possui afinidade com as áreas de Manejo Integrado de Plantas Daninhas, Fertilidade do Solo, Manejo do Solo, Irrigação e Agricultura Geral. Trabalhou com manejo da cultura da mandioca e misturas de herbicidas em tanque. Foi integrante do grupo PET-Agronomia UFRA de 2017 à 2019 onde desenvolveu atividades de pesquisa, ensino e extensão. Atualmente desenvolve pesquisa para tecnologia de aplicação de herbicidas pré-emergentes em taxa variável.

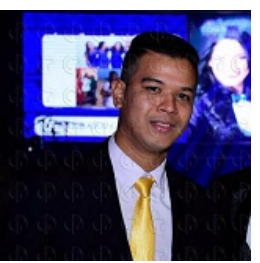

\section{LEANDRO DO ROSARIO SILVA}

Engenheiro Agrônomo formado pela Universidade Federal Rural da Amazônia - Foi bolsista do Programa de Educação Tutorial PET Agronomia (PET-Agronomia/SeSu/MEC) - Sócio e diretor da L B Projetor e Soluções Agropecuárias LTDA. 


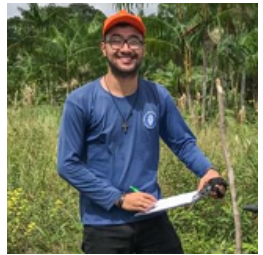

DANIEL COSTA NOGUEIRA

Possui graduação em Administração pela Universidade Federal do Pará (2012). Atualmente graduando em Agronomia pela Universidade Federal Rural da Amazônia (2016). Vinculado ao Programa de Educação Tutorial Agronomia UFRA PET Agronomia UFRA (2017) como bolsista.

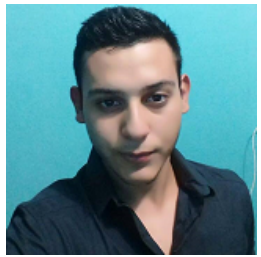

\section{FRANCISCO RONALDO CARDOSO DA} SILVA

Graduando em Agronomia na Universidade Federal Rural da Amazônia, bolsista do grupo PET Agronomia.

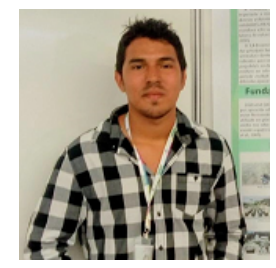

\section{MARTINHO MELO FIGUEIREDO}

Graduando em Agronomia na Universidade Federal Rural da Amazônia, bolsista do grupo PET Agronomia.

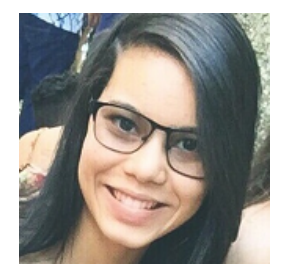

\section{TREYCE STEPHANE CRISTO TAVARES}

Graduanda em Agronomia na Universidade Federal Rural da Amazônia (UFRA). É, atualmente, integrante do grupo de pesquisa Manejo Integrado de Plantas Daninhas da Amazônia (MIPDAM), além de monitora de Manejo Integrado de Plantas Daninhas / Manejo de Plantas Daninhas em Pastagens. Integrante do Programa de Educação Tutorial - PET Agronomia.

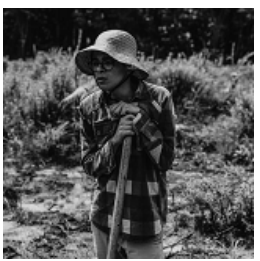

PHELIPE HENRIQUE COSTA DE MIRANDA Bolsista no Programa de Educação Tutorial - PET Agronomia (2021), monitor das disciplinas Manejo Integrado de Plantas Daninhas e Manejo de Plantas Daninhas em Pastagens (2018 - 2020), Voluntário no programa de iniciação científica PVIC (2018 - 2019), estagiário no grupo de pesquisa de Manejo Integrado de Plantas Daninhas na Amazônia MIPDAM (2018 - 2020). Tem experiência na

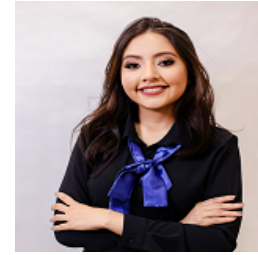

\section{GABRIELA TAVARES PIRES}

Mestranda em Genética e Melhoramento de Plantas na Universidade Estadual do Norte Fluminense Darcy Ribeiro. Engenheira Agrônoma pela Universidade Federal Rural da Amazônia - Campus Belém. Foi bolsista do Programa de Educação Tutorial PET Agronomia (PETAgronomia/SeSu/MEC). Foi estagiária do Laboratório de Recursos Genéticos e Biotecnologia da Empresa Brasileira de Pesquisa Agropecuária (EMBRAPA Amazônia Oriental).

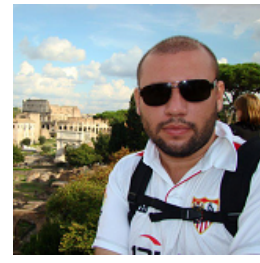

\section{RAFAEL GOMES VIANA}

Engenheiro Agrônomo graduado na Universidade Federal Rural da Amazônia (2003), Mestre (2006) e Doutor em Fitotecnia na Universidade Federal de Viçosa (2010) com período sanduíche em Fitossanidade na Universitat de Lleida-Espanha. Atualmente é professor Associado I da Universidade Federal Rural da Amazônia no Campus de Belém, tutor do grupo PET Agronomia e pesquisador líder do grupo de pesquisa Manejo Integrado de Plantas Daninhas na Amazônia (MIPDAM). 